\title{
Efficacy and safety of plant-based therapy on recurrent aphthous stomatitis and oral mucositis in the past decade: a systematic review
}

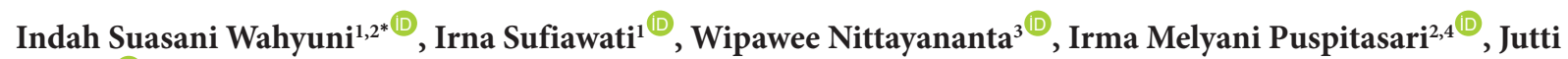 \\ Levita $^{2}{ }^{\mathbb{D}}$ \\ ${ }^{1}$ Faculty of Dentistry, Universitas Padjadjaran, Bandung, Indonesia \\ ${ }^{2}$ Faculty of Pharmacy, Universitas Padjadjaran, Sumedang, Indonesia \\ ${ }^{3}$ Faculty of Dentistry, Thammasat University, Pathum Thani, Thailand \\ ${ }^{4}$ Center of Excellence in Higher Education for Pharmaceutical Care Innovation, Universitas Padjadjaran, Sumedang, Indonesia
}

\section{A R T I C LE INF O}

Article Type:

Review

\section{Article History:}

Received: 2 July 2020

Accepted: 29 September 2020

\section{Keywords:}

Anti-inflammatory

Efficacy

Oral mucosa

Plant-based

Safety

Stomatitis

\begin{abstract}
A B S T RAC T
Oral mucosal inflammation is one of the oral diseases causing pain and reducing the quality of human life. The types of oral mucosal inflammation that commonly found were recurrent aphthous stomatitis (RAS) and oral mucositis (OM). Anti-inflammatory drugs, both synthetic and plant-based, have been used to treat RAS and OM. Plant-based drugs have been attracted the attention of some researchers to minimize the side effects of synthetic drugs. However, a comprehensive review addressing the use of plant-based drugs for RAS and OM therapy, including drug formulation and species of plant, has not yet been reported. Here, we reported the article review of 9 publications derived from the databases of PubMed, ScienceDirect, Cochrane Library, and other additional relevant works, in order to find the effectiveness and safety of plant-based drugs for RAS and OM therapy. This review was written by following the PRISMA guidelines, and the risk of bias of the articles was evaluated using the Oxford Quality Scoring System. It was found that the effective and safe drugs for RAS therapy contained acemannan from Aloe vera and curcumin from Curcuma longa, both in an oral gel formulation. For OM therapy, drugs contained curcumin from Curcuma longa; licorice from Glycyrrhiza glabra; Aloe vera and black mulberry from Morus nigra, in soft tablet, mouthwash solution or mucoadhesive film formulation. In conclusion, the most effective and safest plant-based therapy for RAS is Acemannan $0.5 \%$ in oral gel, whereas for OM is Licorice root extract $0.18 \mathrm{mg}$ in mucoadhesive film.
\end{abstract}

Implication for health policy/practice/research/medical education:

This systematic review might be useful for developing the clinical guideline of plant-based drugs for RAS and OM.

Please cite this paper as: Wahyuni IS, Sufiawati I, Nittayananta W, Puspitasari IM, Levita J. Efficacy and safety of plant-based therapy on recurrent aphthous stomatitis and oral mucositis in the past decade: a systematic review. J Herbmed Pharmacol. 2021;10(2):179-187. doi: 10.34172/jhp.2021.19.

\section{Introduction}

Human oral mucosa inflammation may occur in the form of ulcerated lesions or erosions. The pain caused by these diseases frequently reduces the quality of life due to its disadvantage effect on oral functions $(1,2)$. The antiinflammatory drugs, administered orally or topically, are needed, however, there are only limited available drugs. The topical treatment of oral mucosa often encounters several problems due to the specific characters of the mouth. The mouth comprises of a special tissue structure moistened by saliva and digestive enzymes. The possibility of interference due to the function of mastication requires a tolerable taste. Nonetheless, topical treatment is still in use due to its benefits in reducing the risk of adverse events and side effects. Systemic treatment for oral mucosal inflammation is needed for a chronic condition or when the patient is not responsive to topical therapy (3).

The common oral mucosa inflammations which have been widely researched in the past decade are recurrent aphthous stomatitis (RAS)/oral ulcer and oral mucositis 
(OM). RAS is characterized by pain and ulcerated lesions. Currently, RAS is treated with topical or systemic steroids or nonsteroids, supplementation support, and immunomodulatory or anti-inflammatory drugs $(1,2)$. $\mathrm{OM}$ is an acute inflammation often found during or following cancer therapy (chemotherapy, radiotherapy, or a combination of both). The clinical features are widespread painful erosions and/or ulceration of the oral mucosa, which sometimes affects the continuity of cancer therapy. OM therapy is chlorhexidine, a broad-spectrum antimicrobial, and antiseptic agent, but this drug possesses unpleasant taste and causes tooth discoloration $(4,5)$. Therefore, the development of effective and safer plantbased oral mucosal inflammation therapy is needed.

A previous systematic review article reported the effectiveness and safety of topical agents for RAS therapy, but no study has been published on the use of plant-based ones (6). Another article review reported the therapy for OM, but the recommendations in using plant-based drugs are not found (7). Our search on the Cochrane Library database did not found articles on plant-based drugs for oral mucosa inflammation. Here, we reported a systematic review developed from the latest evidencebased medicine research, to become a recommendation for clinical guideline of plant-based drugs for oral mucosa inflammation therapy. Moreover, this review can be implemented as a reference for the development of further researches on plant-based oral mucosa anti-inflammatory drug discovery.

\section{Materials and Methods}

This systematic review was written by following the Preferred Reporting for Systematic Reviews and MetaAnalysis (PRISMA) guidance. The PICOS items, i.e., population, intervention, comparator, outcomes, and study design are detailed below (8).

Two population groups, namely RAS and OM, were classified, based on the differences of the therapeutic principles, duration of treatment, efficacy, and safety parameters of anti-inflammatory treatment. The homogeneity of the RAS and OM patients was determined by the inclusion and exclusion criteria mentioned in these articles. In the OM group, the types of malignancy/cancer were not distinguished; however, head and neck cancer with radiotherapy was the common treatment in this population.

In this review, the interventions analyzed were the administration of plant-based anti-inflammatory drugs, resulting in post-therapeutic targets, in the form of efficacy and safety of the drugs. These post-therapeutic targets were determined by standard measurable parameters. The intervention was accompanied by a comparator in the form of an intervention group with established standard treatment, or a positive/negative control group.

The expected outcome of this review was the efficacy and safety of the use of plant-based medicine for RAS (6) and OM (7). Drug efficacy in RAS therapy was determined by clinical parameters, namely: pain score, number, size, and duration of the ulcer; while the safety parameters included: side effects and adverse events, including hematology laboratory tests, and irritation tests (6). In OM therapy, the efficacy parameters were pain score, OM score, and the possibility of abnormal oral intake, while safety parameters also looked at the side effects and adverse events; besides the measurement of patients' body weight; and other treatments need during therapy. In addition to OM, the side effects of cancer therapy, whether radiotherapy, chemotherapy, or a combination of both, which are directly related to the oral cavity disruption, could be nausea, dry mouth, and/or oral candidiasis infection. These conditions could affect the efficacy of drug use, therefore, drug adherence or the emergence of oral candidiasis also became a parameter (7).

Several clinical trial studies of stomatitis were searched in the electronic database of PubMed, ScienceDirect, and Cochrane Library. Other additional relevant works were obtained from the citations in the selected articles. The literature search was performed on June 5th-8th, 2020. The keywords used were ("stomatitis" [MeSH Terms] OR stomatitis [Text Word]) AND ("anti-inflammatory agents" [All Fields] OR “anti-inflammatory agents” [MeSH Terms] OR anti-inflammatory agents [Text Word]). The detailed diagram and process of literature search and the results obtained are depicted in Figure 1 and Table 1, respectively.

Inclusion criteria were plant-based or herbal clinical trial studies, available and accessible full texts, and Englishwritten articles published in the past decade between January 1, 2010, and May 31, 2020. Non-oral mucosa inflammation/stomatitis, in vivo/in vitro/in silico studies, non-plant-based, or incomplete study, were not included in this study. The titles and the abstracts of the articles included were screened for relevance with the aim of the study, by ISW and JL, independently. The references in the articles included were also assessed to look for additional

Identification

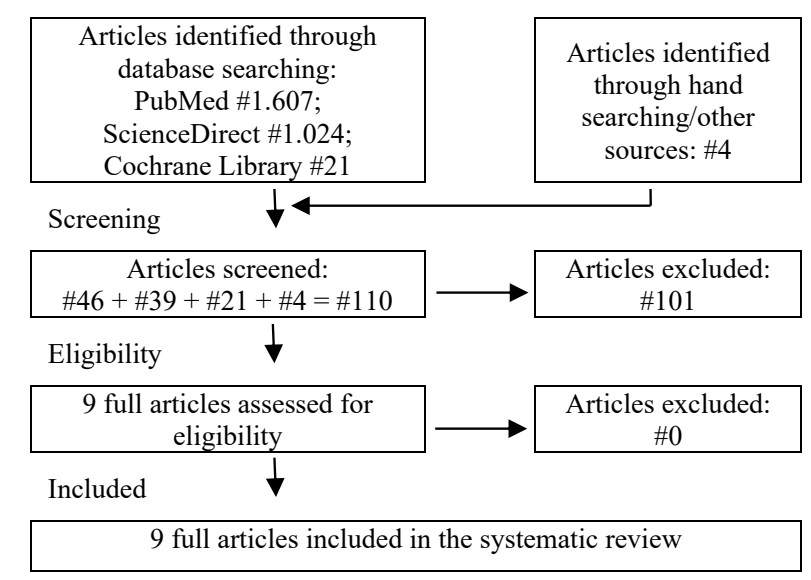

Figure 1. PRISMA flowchart of this systematic review. 
Table 1. Literature search results from PubMed, ScienceDirect, and Cochrane Library

\begin{tabular}{|c|c|c|c|}
\hline Step No. & PubMed & ScienceDirect & Cochrane Library \\
\hline 1 & Stomatitis \#29.543 & Stomatitis \#41.702 & Stomatitis \#3886 \\
\hline 2 & Antiinflammatory agent \# 569.257 & Antiinflammatory agent \#35.369 & Antiinflammatory agent \#4808 \\
\hline 3 & Combine 1 AND $2 \# 1.607$ & Combine 1 AND 2 \#1.024 & Combine 1 AND $2 \# 21$ \\
\hline 4 & $\begin{array}{l}\text { Limit to: Clinical trials, English, Humans, } 10 \\
\text { years, Full-text \#46 }\end{array}$ & Limit to: Clinical trials, 10 years \#39 & Limit to Trial \#21 \\
\hline 5 & $\begin{array}{l}\text { Excluded \#41 } \\
-\quad \text { Non plant-based and non-oral mucosa } \\
\text { inflammation or stomatitis \#10, } \\
-\quad \text { non plant-based \#24, } \\
-\quad \text { non-oral mucosa inflammation/ } \\
\text { stomatitis \#1, } \\
\text { - } \quad \text { incomplete study \#6 }\end{array}$ & $\begin{array}{l}\text { Excluded \#39 } \\
\text { - Not relevant with the topic\#15, } \\
\text { - } \text { Review articles or critical analysis \#7, } \\
\text { - Non plant-based and non-oral mucosa } \\
\text { inflammation or stomatitis \#3, } \\
\text { - Non plant-based \#4 } \\
\text { - Non-oral mucosa inflammation or } \\
\text { stomatitis \#3 } \\
\text { - In vivo study \#3 } \\
\text { - In vitro study \#3 } \\
\text { - In silico study \#1 }\end{array}$ & $\begin{array}{l}\text { Excluded \#20 } \\
\text { - Non plant-based and non-oral } \\
\text { mucosa inflammation/stomatitis } \\
\# 12, \\
-\quad \text { Non plant-based \#3, } \\
-\quad \text { Non-oral mucosa inflammation/ } \\
\text { stomatitis \#1, } \\
\text { - Incomplete study \#4 }\end{array}$ \\
\hline 6 & Selected \#5 & Selected \#0 & Selected \#1 \\
\hline 7 & $\begin{array}{l}\text { Hand search for relevant articles from } \\
\text { references } \# 4\end{array}$ & $\begin{array}{l}\text { Hand search for relevant articles from } \\
\text { references } \# 0\end{array}$ & $\begin{array}{l}\text { Hand search for relevant articles from } \\
\text { references } \# 0\end{array}$ \\
\hline 8 & Final Selected \#9 & & \\
\hline
\end{tabular}

relevant studies. If disagreements were found, discussions and decision-making were carried out according to mutual agreement. There was no difference in deciding the eligible and included articles for review writing. The eligible and included articles were then reviewed for relevant data or important pieces of information needed. Information related to population (country, number of subjects, oral disease type), type of intervention (drug formulation), comparator group, and study outcome (efficacy and safety) were extracted by ISW.

The controlled clinical trial articles were assessed for the risk of bias and quality using the Oxford Quality Scoring System (9), by ISW. The assessment was carried out using an available online software (http://www.pmidcalc. org/? sid=8721797\&newtest $=$ Y). The results of the risk of bias assessment for controlled clinical trial articles, 8 out of 9, are detailed in Table 2. The high range of quality articles was used for qualitative analysis in recommending treatment. The Oxford Quality Scoring System consisted of 5 questions, as shown in the note of Table 2 as follows. The maximum score was five, and the minimum score was -2 . The total score of -2 to 2 shows the low range of quality score, while the total score of 3 to 5 shows the high range of quality score (9).

\section{Results}

Table 3 shows the general summary of the articles included in the review. The studies were conducted in Thailand (10), Turkey (11), Iran (12-14), India $(5,15,16)$, and Israel (17). Oral mucosa inflammation treatment as an anti-inflammatory therapeutic goal consisted of 2 articles of RAS $(10,16)$ and 7 articles of OM $(5,11-15,17)$.

Table 2. Assessment of the risk of bias for the controlled clinical trial

\begin{tabular}{|c|c|c|c|c|c|c|}
\hline \multirow{2}{*}{ Reference } & \multicolumn{5}{|c|}{ Question No. } & \multirow{2}{*}{ Result } \\
\hline & [1] & [2] & [3] & [4] & [5] & \\
\hline Bhalang et al, 2013 (10) & 1 & 1 & 1 & 1 & 0 & High range of quality \\
\hline Delavarian et al, 2019 (12) & 1 & 1 & 1 & 1 & 1 & High range of quality \\
\hline Ghalayani et al, 2014 (13) & 1 & 1 & 1 & 1 & 1 & High range of quality \\
\hline Harman et al, 2019 (11) & 0 & -1 & 0 & -1 & 1 & Low range of quality \\
\hline Saldanha and Almeida, 2014 (15) & 0 & -1 & 0 & -1 & 0 & Low range of quality \\
\hline Sahebjameea et al, 2014 (14) & 1 & 1 & 1 & 1 & 0 & High range of quality \\
\hline Patil et al, 2015 (5) & 1 & 1 & 0 & -1 & 0 & Low range of quality \\
\hline Deshmukh and Bagewadi, 2014 (16) & 1 & 1 & 1 & -1 & 1 & High range of quality \\
\hline
\end{tabular}

Note: Question No. 1. was the study described as random? (Yes $=1$, No $=0) ; 2$. was the randomization scheme described and appropriate? $($ Yes $=1$, No $=-1)$; 3 . was the study described as double-blind? (Yes =1, No =0); 4 . was the method of double blinding appropriate? $($ Yes $=1$, No $=-1)$; 5 . was there a description of dropouts and withdrawals? (Yes $=1$, No $=0$ ) (9). 
Table 3. A general summary of the articles included in the review

\begin{tabular}{|c|c|c|c|c|c|c|}
\hline Reference & Country of Research & Number of Patients & Study Design & Type of Oral Inflammation & Antiinflammation & Drugs Formula \\
\hline Bhalang et al, 2013 (10) & Thailand & 180 & RCT & RAS & $\begin{array}{l}\text { Acemannan } 0.5 \% \text { (extracted from aloe vera) in } \\
{\text { Carbopol }{ }^{\circledR} \text { _934Polymer United States Pharmacopeia/National }} \text { Formulary (Carbopol }{ }^{\circledR} \_934 \mathrm{P} \text { NF) }\end{array}$ & Oral gel \\
\hline Delavarian et al, 2019 (12) & Iran & 32 & RCT & OM & Curcumin-loaded nanomicelles $80 \mathrm{mg}$ & Soft tablets \\
\hline Ghalayani et al, 2014 (13) & Iran & 60 & RCT & OM & $\begin{array}{l}\text { Licorice root/Glycyrrhiza glabra extract (polyphenols as pyrogallol) } \\
0.18 \mathrm{mg} / \text { film }\end{array}$ & Mucoadhesive gel \\
\hline Saldanha and Almeida, 2014 (15) & India & 40 & Non-RCT & OM & Curcumin $3 \%$ ( $1.5 \mathrm{~g}$ turmeric powder $+50 \mathrm{~mL}$ of water) & Mouthwash \\
\hline Sahebjamee et al, 2014 (14) & Iran & 26 & RCT & OM & Aloe vera mouthwash (pure Aloe vera gel; Barij Aloe vera syrup) & Mouthwash \\
\hline Patil et al, 2015 (5) & India & 20 & RCT & $\mathrm{OM}$ & Curcumin mouth rinse $0.004 \%$ & Mouthwash \\
\hline Deshmukh and Bagewadi, 2014 (16) & India & 60 & RCT & RAS & $\begin{array}{l}\text { Curcuma longa extract } 10 \mathrm{mg} / \mathrm{g} \text { (Curenext oral gel; Abbott } \\
\text { Pharmaceuticals). }\end{array}$ & Oral Gel \\
\hline Elad et al, 2013 (17) & Israel & 7 & Case series & OM & $\begin{array}{l}\text { Curcuma tincture (curcumin complex } 3 \text { (C3) 95\%, turmeric, and } \\
\text { ginger dissolved with glycerin } 0.4 \% \text { alcohol) }\end{array}$ & Mouthwash \\
\hline
\end{tabular}

Abbreviations: RAS, Recurrent aphthous stomatitis; OM, oral mucositis. 
The number of subjects consisted of 7 to 180 subjects per article, with a total of 240 patients diagnosed with RAS and 275 with OM. In this review, there are 6 articles with randomized controlled/comparative clinical trial (RCT) design $(5,10,12-14,16), 2$ articles in cohort/prospective non-randomized clinical trial (NRCT) design $(11,15)$, and 1 article is a case series (17).

The plant-based anti-inflammatory drugs mostly contain curcumin from Curcuma longa $(5,12,15,16,17)$, acemannan from Aloe vera $(10,14)$, licorice root from Glycyrrhiza glabra (13), and black mulberry from Morus nigra (11). The drug formulations were: oral gel/ mucoadhesive gel as a topical application over the lesions in 3 articles $(10,13,16)$, mouthwash solution in 5 articles $(5,11,14,15,17)$, and soft tablet in 1 article (12).

The effectiveness and safety of the drugs were determined using several parameters, and by comparing with the control group using a placebo, saline, or with the commonly prescribed drugs, such as triamcinolone acetonide, benzydamine hydrochloride, and chlorhexidine. There are 2 articles of plant-based products (acemannan/ Aloe vera and curcumin/turmeric) for RAS therapy, using triamcinolone acetonide $0.1 \%$ as a positive control. Both showed no different effectiveness compared to a positive control $(10,14)$, but the acemannan oral gel was reported to be safe through blood and dermatitis tests (10).

For OM therapy, the effectiveness of curcumin was better compared to that of saline mouthwash (15), chlorhexidine (5), and placebo $(12,17)$. Curcumin was reported safe because it was well-tolerated, without adverse events and oral or systemic side effects $(5,12,17)$. OM treatment using licorice root mucoadhesive film showed efficacy and safety equivalent to triamcinolone acetonide mucoadhesive film (13), and the use of pure Aloe vera mouthwash showed equivalent to benzydamine mouthwash (14). Treatment with black mulberry syrup showed less mucositis than benzydamine and chlorhexidine mouthwash (11).

Table 4 shows a summary of the efficacy and safety parameters of anti-inflammatory plant-based drugs and related results in oral mucosa inflammation therapy. The effectiveness of anti-inflammatory therapy for RAS was measured through clinical parameters: pain intensity using visual analog scale/VAS of 0-10 and size of ulcer in 2 articles $(10,16)$. Other clinical parameters are: the number of ulcers and duration of ulcer period only observed in 1 article (16). Therapeutic safety parameters were performed by monitoring adverse effects or side effects following drug therapy, blood test/complete blood count, liver and renal function parameters. The dermatitis reaction scale was also measured to assess the local and systemic side-effects only in 1 article and used on the normal oral mucosa of 50 healthy volunteers (10).

The efficacy and safety parameters of anti-inflammatory drugs and related results in OM therapy were measured before and after the therapy period. The assessment of
OM scores used included the National Cancer Institute Common Toxicity Criteria version 2 scale (NCI-CTC v.2) (12), WHO OM grading system $(11,13,14,17)$, the Oral Mucositis Assessment Scale (OMAS) $(5,17)$, and a self-prepared and validated tool for assessing OM, Grade I - IV (15). Clinical examination was performed covering all areas of the oral mucosa with ulceration or erythema lesions. Oral mucosa includes the upper labial mucosa, lower labial mucosa, right buccal mucosa, left buccal mucosa, right lateral and ventral tongue, left lateral and ventral tongue, floor of the mouth, soft palate/fauces, and hard palate (18).

The parameters for pain were: $\mathrm{OM}$ related pain relief $(13,14)$, a self-prepared and validated tool for assessing pain in mild, moderate, and severe degree (15), a numerical rating scale for pain (5), and VAS scoring 0-10 (17). The effectiveness of therapy was also determined by the tolerability of oral intake $(13,14)$. The safety parameters of treatment were done by recording adverse events and side effects $(14,17)$, or by measuring weights of patients before and after the radiotherapy courses $(12,13)$, or by recording the other treatment needs such as artificial saliva supplement/anti-infection medications/the need for hospitalization/the addition of nutritional support/ feeding tube (13). None of the articles being reviewed, analyzed the overall oral health-related quality of life, before and after therapy.

\section{Discussion}

The development of plant-based medicines is performed especially in Asian countries, including Indonesia (19), Malaysia (20), Thailand (10,21), India (22), Korea (23), China (24), Japan $(25,26)$, Iran $(12,13,27)$, Turkey (11), Saudi Arabia (28), and Israel (17). in the countries mentioned above, herbal medicines have been used in traditional treatment for a long time. The development of traditional into scientifically recognized medicines has been done as an effort to find alternatives to chemical synthesis treatments that have been used as a standard treatment so far. The side effect, adverse events, and costeffectiveness are also a consideration for the development of plant-based medicine. Even, in a developed country like Japan, dentists are also trained to master traditional medicine, such as Kampo medicine, which is needed for dental and oral disease therapy in addition to Western medicine (26).

Standard therapy for oral mucosa inflammation e.g. a steroid (Triamcinolone acetonide, Dexamethasone) or non-steroid (Benzydamine $\mathrm{HCl}$, Hyaluronic acid), resulted in some disadvantages, i.e.: some possible adverse effects from steroid treatment, the potential of secondary oral candidiasis development, unpleasant taste and teeth discolorization, especially from long-term use $(1,2,29)$. Therefore an alternative therapy is needed to treat inflammation of the oral mucosa. 
Table 4. Results and outcome of the efficacy and safety parameters of plant-based anti-inflammatory therapy

\begin{tabular}{|c|c|c|c|c|c|}
\hline Reference & Anti-inflammation & Efficacy parameters & Safety parameters & Result & Outcome \\
\hline \multicolumn{6}{|c|}{ RAS } \\
\hline Bhalang et al, 2013(10) & $\begin{array}{l}\text { Acemannan } 0.5 \% \text { oral gel } \\
\text { (extracted from Aloe vera) }\end{array}$ & $\begin{array}{l}\text { 1. Pain VAS } \\
\text { 2. Size of ulcer }\end{array}$ & $\begin{array}{l}\text { 1. Adverse effects or side } \\
\text { effects } \\
\text { 2. Blood test/complete blood } \\
\text { count, liver and renal } \\
\text { function parameter } \\
\text { 3. Dermatitis reaction }\end{array}$ & $\begin{array}{l}\text { 1. Decrease in ulcer size significantly. } \\
\text { 2. None of the adverse effect/side effect/ systemic disturbance/ } \\
\text { dermatitis reaction. }\end{array}$ & $\begin{array}{l}\text { Acemannan } 0.5 \% \text { oral gel }=0.1 \% \\
\text { Triamcinolone acetonide. }\end{array}$ \\
\hline $\begin{array}{l}\text { Deshmukh and Bagewadi, } \\
2014 \text { (16) }\end{array}$ & $\begin{array}{l}\text { Curcuma longa extract } 10 \\
\mathrm{mg} / \mathrm{g} \text { (Curenext oral gel, } \\
\text { Abbott Pharmaceuticals). }\end{array}$ & $\begin{array}{ll}\text { 1. } & \text { Pain VAS } \\
\text { 2. } & \text { Size } \\
\text { 3. } & \text { Number of ulcers } \\
\text { 4. } & \text { Duration of ulcer period }\end{array}$ & Not mentioned & $\begin{array}{l}\text { 1. A significant difference between the pain score, size, number, } \\
\text { and duration of ulcers from day } 0 \text {-day } 7 \text {. } \\
\text { 2. Similar effectivity with } 0.1 \% \text { triamcinolone acetonide in minor } \\
\text { RAS. }\end{array}$ & $\begin{array}{l}\text { Curcuma longa extract } 10 \mathrm{mg} / \mathrm{g} \\
\text { oral gel }=0.1 \% \text { Triamcinolone } \\
\text { acetonide. }\end{array}$ \\
\hline \multicolumn{6}{|c|}{ OM } \\
\hline Delavarian et al, 2019 (12) & $\begin{array}{l}\text { Curcumin-loaded nanomicelles } \\
80 \mathrm{mg} \text { soft tablet }\end{array}$ & NCl-CTC v.2 & $\begin{array}{l}\text { Weights of patients before and } \\
\text { after the radiotherapy courses }\end{array}$ & $\begin{array}{l}\text { Study group: only } 32 \% \text { developed OM with no obvious oral or } \\
\text { systemic side effects; better than placebo in OM prevention and } \\
\text { reducing severity. }\end{array}$ & $\begin{array}{l}\text { Curcumin-loaded nanomicelles } 80 \\
\text { mg soft tablet >placebo. }\end{array}$ \\
\hline Ghalayani et al, 2014 (13) & $\begin{array}{l}\text { Licorice root/Glycyrrhiza glabra } \\
\text { extract mucoadhesive film } \\
0.18 \mathrm{mg}\end{array}$ & $\begin{array}{l}\text { WHO OM grading system, } \\
\text { Oral intake, OM-related pain } \\
\text { relief. }\end{array}$ & $\begin{array}{l}\text { Weights of patients before and } \\
\text { after the radiotherapy courses, } \\
\text { Other treatment needs. }\end{array}$ & $\begin{array}{l}\text { Licorice effective, safe, and can be used in OM therapy, in } \\
\text { reducing pain during radiotherapy. }\end{array}$ & $\begin{array}{l}\text { Licorice root extract muco-adhesive } \\
\text { films } 0.18 \mathrm{mg}=\text { Triamcinolone } \\
\text { acetonide } 0.1 \% \text {. }\end{array}$ \\
\hline $\begin{array}{l}\text { Saldanha and Almeida, } \\
2014 \text { (15) }\end{array}$ & $\begin{array}{l}\text { Curcumin } 3 \% \text { mouthwash }(1.5 \\
\text { g of turmeric powder }+50 \mathrm{~mL} \\
\text { water) }\end{array}$ & $\begin{array}{l}\text { A self-prepared and validated } \\
\text { tool for assessing OM (Grade } \\
I-I V \text { ) and for pain score. }\end{array}$ & Not mentioned & $\begin{array}{l}\text { Turmeric (curcumin) and saline mouthwash were statistically } \\
\text { significant in reducing the severity of OM, but turmeric was } \\
\text { better than saline mouthwash. }\end{array}$ & $\begin{array}{l}\text { Curcumin } 3 \% \text { mouthwash }>\text { saline } \\
0.9 \% \text { mouthwash. }\end{array}$ \\
\hline Sahebjamee et al, 2014 (14) & $\begin{array}{l}\text { Aloe vera mouthwash (pure } \\
\text { Aloe vera gel/Barij Aloe } \\
\text { vera syrup; Barij Essence } \\
\text { Pharmaceutical Co.; Kashan, } \\
\text { Iran) }\end{array}$ & $\begin{array}{l}\text { WHO OM grading system, } \\
\text { Oral intake, OM-related pain } \\
\text { relief. }\end{array}$ & Adverse event and side effect. & $\begin{array}{l}\text { Maximum OM grade occurrence was at day } 23.3 \text { (Aloe vera } \\
\text { group) and day } 23.5 \text { (benzydamine group). } \\
\text { Early signs of mucositis } 15.6 \text { days (Aloe vera group) and } 15.8 \text { days } \\
\text { (benzydamine group). Nausea in Aloe vera group } 15.4 \% .\end{array}$ & $\begin{array}{l}\text { Pure } \text { Aloe vera mouthwash }= \\
\text { benzydamine mouthwash. }\end{array}$ \\
\hline Patil et al, 2015 (5) & Curcumin mouth rinse $0.004 \%$ & $\begin{array}{l}\text { OMAS, WHO OM grading } \\
\text { system, NRS for pain. }\end{array}$ & Adverse event & $\begin{array}{l}\text { Wound healing and patient compliance in Curcumin group better } \\
\text { than chlorhexidine. } \\
\text { Adverse events in the Curcumin mouthwash group (-), Less oral } \\
\text { candida infection in Curcumin group, }\end{array}$ & $\begin{array}{l}\text { Curcumin mouth rinse } 0.004 \%> \\
\text { chlorhexidine mouthwash. }\end{array}$ \\
\hline Elad et al, 2013 (17) & $\begin{array}{l}\text { Curcuma tincture (curcumin } \\
\text { C3 95\%, turmeric and ginger } \\
\text { dissolved with glycerin } 0.4 \% \\
\text { alcohol) }\end{array}$ & $\begin{array}{l}\text { OMAS, WHO OM grading } \\
\text { system, VAS 0-10 for pain } \\
\text { scale. }\end{array}$ & Adverse event & $\begin{array}{l}\text { All the subjects }(n=7) \text { have OM with minimal score } 1 \text { (maks WHO } \\
=2 \text {; maks OMAS }=5 \text {; maks VAS }=7 \text { ). } \\
\text { No oral adverse event. }\end{array}$ & $\begin{array}{l}\text { Curcumin tincture }>\text { placebo, but } \\
\text { further research needed with more } \\
\text { subjects. }\end{array}$ \\
\hline
\end{tabular}

Abbreviations: RAS, Recurrent aphthous stomatitis; OM, oral mucositis; VAS, visual analog scale; NRS, Numerical Rating Scale. 
Medicinal plants that have shown anti-inflammatory activity for oral mucosal inflammation, such as Aloe vera $(10,14)$, Black mulberry/Morus nigra (11), Licorice/ Glycyrrhiza glabra (13), and Turmeric plant/Curcuma longa (5,12,15-17). The bioactive constituents are acemannan (PubChem CID: $\quad 72041)$ in Aloe vera; papyriflavonol A (ChemSpider ID8518529), kuraridin (PubChem CID 44428631), and flavanone (PubChem CID: 10251) in black mulberries; pyrogallol (PubChem CID: 1057) as polyphenols in licorice root; and Curcumin (PubChem CID: 969516) as flavonol/flavonoid in Curcuma longa/turmeric plant.

Acemannan is mucopolysaccharide present in the inner gel of the Aloe vera's leaf (Asphodelaceae). Acemannan has been proven to have a significant role in oral wound healing in rats. It can induce the fibroblast proliferation and stimulation of oral mucosa growth factors expressions. It also has been proven to increase the synthesis of collagen and glycosaminoglycan synthesis (29). The Aloe vera mouthwash was reported safe in oral mucosa inflammation therapy without side effects $(10,14)$.

The flavanone contained in black mulberry/Morus nigra (Moraceae) leaves extract has proven as an antiinflammatory agent. It can inhibit the formation of granulomatous tissues in chronic inflammation and reduce the volume of paw edema in rats. The total flavonoid in M. nigra fruit extracts also has been reported to inhibit the xylene-induced ear edema and carrageenaninduced paw edema in mice, accompanied by decreased levels of several pro-inflammatory cytokines (IL-1, TNFalpha, and IFN-gamma). In vitro study showed decreased levels of NO in LPS-stimulated RAW264.7 cells, without showing the cytotoxicity effect (30).

Licorice/Glycyrrhiza glabra (Leguminosae) has several phytochemistry constituents that play an important role as steroid-like antiinflammation similar to hydrocortisone, i.e.: polyphenol (13) and saponin (glycyrrhizin and glycyrrhizic acid) (31). These chemical constituents can inhibit the activity of phospholipase A2 and cyclooxygenase resulted in inhibition of prostaglandin formation (PGE2), which is critical in inflammatory processes. The in vitro research has also proved that glycyrrhizic acid inhibits the activity of platelet aggregation. Moreover, elevated blood pressure was one of the most commonly reported side effects of licorice supplementation (31).

Curcumin is a secondary metabolite found in Curcuma longa/turmeric plant (Zingiberaceae). It has antiinflammatory properties (32) and the ability to inhibit the synthesis of prostaglandins through cyclooxygenase and lipoxygenase activity blockade (16). Simultaneously, the production of prostaglandin, leukotriene, and neutrophil function is inhibited during the inflammatory condition (16).

The drug formula for oral mucosa inflammation therapy is prepared by considering the effectiveness of the administration route, nature of the disease, characteristics of the oral mucosa, widespread lesions, number of lesions, and the affordability during drug application. The oral cavity is always wet and moist, so medications for oral mucosa require the right formulation $(3,32)$. Plant-based drugs in mucoadhesive gel/oral gel formula for oral mucosa inflammation therapy has been proven to increase therapeutic effectiveness equivalent to the administration of triamcinolone acetonide (steroids) as a standard control $(10,13,16)$.

A clinical trial of plant-based drugs in solution formula (mouthwash, tincture, pure juice, dan syrup) showed better result compared to control analgesic anti-inflammatory benzydamine $\mathrm{HCl}(11,14)$, or antiseptic chlorhexidine $(5,11)$, or normal saline $0.9 \%(15)$, or placebo $(12,17)$, but so far we haven't found any plant-based drug that compares with steroids in liquid formulas, for oral mucosa inflammation therapy.

A review of articles for RAS therapy has been published with the intervention of selected topical agents, nonplant-based. The review recommends that treatments with topical corticosteroids are likely to be effective in treating RAS than other selected topical drugs such as benzydamine hydrochloride, topical tetracycline, and topical antiseptics chlorhexidine (6). Another review article on "Current Trends in Management of Oral Mucositis in Cancer Treatment", states that palifermin has proven as a prospective agent, nonetheless the cost-effectiveness has to be considered since no single or combinations of drugs are available. Therefore, the prevention and management of OM by reducing and preventing local and systemic infection will optimize the quality of life. In most cases, pain can be controlled with topical mucosal coating agents containing lidocaine/doxepin, but in more severe cases the topical or systemic corticosteroids can be considered. Topical antifungal therapy should be given in candidiasis emergence. However, for the majority of patients, there are no effective interventions available yet (7).

In our review, we found 5 studies in a high range of quality. There were two studies for RAS therapy, i.e.: Acemannan $0.5 \%$ in an oral gel (10) and Curcuma longa extract $10 \mathrm{mg} / \mathrm{g}$ in an oral gel (16), both showed clinical effectiveness and can reduce pain equivalent to $0.1 \%$ triamcinolone acetonide. Acemannan $0.5 \%$ in oral gel more recommended for clinical use or to be developed in a further clinical trial because it was proven to be safer (blood and dermatitis reaction tests available) (10).

On the other side, there are three studies of OM therapy, i.e.: Curcumin-loaded nano micelles $80 \mathrm{mg}$ in soft tablet (peroral) (12), Licorice root/Glycyrrhiza glabra extract $0.18 \mathrm{mg}$ in the mucoadhesive film (13), and pure Aloe vera gel/Barij Aloe vera syrup mouthwash (14). The efficacy of Licorice root/Glycyrrhiza glabra extract 0.18 $\mathrm{mg}$ in the mucoadhesive film looks superior compared to the other two. Licorice extract showed more effective, 
safe, and can reduce pain in OM during radiotherapy, equivalent to triamcinolone acetonide $0.1 \%$. Thus the use of Licorice root extract $0.18 \mathrm{mg}$ in a mucoadhesive film can be clinically recommended for OM therapy. This mucoadhesive formula has been known to increase the therapeutic effect for inflammation of the oral mucosa better than solution formula, so the use of mucoadhesive formula needs to be considered in the development of further plant-based drugs for oral mucosa inflammation (33).

OM therapy uses Curcumin-loaded nano micelles $80 \mathrm{mg}$ soft tablet and pure Aloe vera mouthwash requires further clinical trials using steroid groups or non-steroidal antiinflammatory groups as a comparator. A new formulation of pure Aloe vera is needed to reduce the nausea side effects and enhance the therapeutic effect. The use of black mulberry and curcumin in solutions formula still requires further clinical trials with blinded randomized study design and more subjects. Based on this review, the proposed-algorithm pharmacotherapy for oral mucosa inflammation is presented in Figure 2.

\section{Conclusion}

The most effective and safest plant-based antiinflammatory drugs for RAS is Acemannan 0.5\% in oral gel and for $\mathrm{OM}$ is Licorice root extract $0.18 \mathrm{mg}$ in mucoadhesive film. Curcumin in turmeric/Curcuma longa, acemannan in Aloe vera, flavonoids in black mulberries/Morus nigra, and polyphenols in licorice/ Glycyrrhiza glabra, can be developed as a prospective antiinflammatory drug, with regular monitoring of systemic organ function, particularly in long term usage.

\section{Authors' contributions}

ISW prepared the manuscript while JL and IMP edited the manuscript. All authors reviewed, confirmed, and approved the final draft.

\section{Conflict of interests}

The authors declare that no conflict of interest is associated with this review.

\section{Ethical considerations}

Ethical issues have been observed by the authors.

\section{Funding/Support}

This project is supported by the Universitas Padjadjaran Internal Grant (RDDU scheme) contract No. 1427/ UN6.3.1/LT/2020.

\section{References}

1. Chavan M, Jain H, Diwan N, Khedkar S, Shete A, Durkar S. Recurrent aphthous stomatitis: a review. J Oral Pathol Med. 2012;41(8):577-83. doi: 10.1111/j.1600-0714.2012.01134.x.

2. Sakly A, De Wever B, Jutla B, Satia M, Bogaert JP. The safety and efficacy of AphtoFix $®$ mouth ulcer cream in the

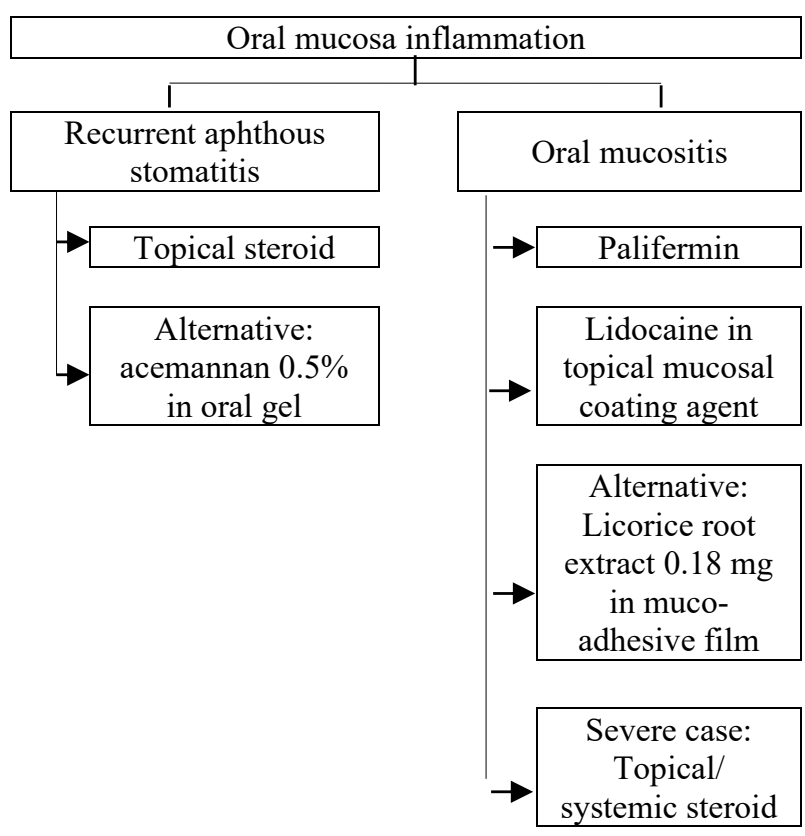

Figure 2. The proposed-algorithm pharmacotherapy for oral mucosa inflammation.

management of recurrent aphthous stomatitis. BMC Oral Health. 2016;16:17. doi: 10.1186/s12903-016-0177-0.

3. Sankar V, Hearnden V, Hull K, Juras DV, Greenberg MS, Kerr AR, et al. Local drug delivery for oral mucosal diseases: challenges and opportunities. Oral Dis. 2011;17 Suppl 1:7384. doi: 10.1111/j.1601-0825.2011.01793.x.

4. Daugèlaitė G, Užkuraitytė K, Jagelavičienė E, Filipauskas A. Prevention and treatment of chemotherapy and radiotherapy induced oral mucositis. Medicina (Kaunas). 2019;55(2). doi: 10.3390/medicina55020025.

5. Patil K, Guledgud MV, Kulkarni PK, Keshari D, Tayal S. Use of Curcumin mouthrinse in radio-chemotherapy induced oral mucositis patients: a pilot study. J Clin Diagn Res. 2015;9(8):ZC59-62. doi: 10.7860/jcdr/2015/13034.6345.

6. Staines K, Greenwood M. Aphthous ulcers (recurrent). BMJ Clin Evid. 2015;2015:1303.

7. Shankar A, Roy S, Bhandari M, Rath GK, Biswas AS, Kanodia R, et al. Current trends in management of oral mucositis in cancer treatment. Asian Pac J Cancer Prev. 2017;18(8):2019-26. doi: 10.22034/apjcp.2017.18.8.2019.

8. Liberati A, Altman DG, Tetzlaff J, Mulrow C, Gøtzsche PC, Ioannidis JP, et al. The PRISMA statement for reporting systematic reviews and meta-analyses of studies that evaluate health care interventions: explanation and elaboration. PLoS Med. 2009;6(7):e1000100. doi: 10.1371/ journal.pmed.1000100.

9. Jadad AR, Moore RA, Carroll D, Jenkinson C, Reynolds DJ, Gavaghan DJ, et al. Assessing the quality of reports of randomized clinical trials: is blinding necessary? Control Clin Trials. 1996;17(1):1-12. doi: 10.1016/01972456(95)00134-4.

10. Bhalang $\mathrm{K}$, Thunyakitpisal $\mathrm{P}$, Rungsirisatean $\mathrm{N}$. Acemannan, a polysaccharide extracted from Aloe vera, is effective in the treatment of oral aphthous ulceration. J 
Altern Complement Med. 2013;19(5):429-34. doi: 10.1089/ acm.2012.0164.

11. Harman M, Ovayolu N, Ovayolu O. The effect of three different solutions on preventing oral mucositis in cancer patients undergoing stem cell transplantation: a non-randomized controlled trial: a Turkish study - nonrandomised trial. J Pak Med Assoc. 2019;69(6):811-6.

12. Delavarian Z, Pakfetrat A, Ghazi A, Jaafari MR, Homaei Shandiz F, Dalirsani Z, et al. Oral administration of nanomicelle curcumin in the prevention of radiotherapyinduced mucositis in head and neck cancers. Spec Care Dentist. 2019;39(2):166-72. doi: 10.1111/scd.12358.

13. Ghalayani P, Emami H, Pakravan F, Nasr Isfahani M. Comparison of triamcinolone acetonide mucoadhesive film with licorice mucoadhesive film on radiotherapy-induced oral mucositis: a randomized double-blinded clinical trial. Asia Pac J Clin Oncol. 2017;13(2):e48-e56. doi: 10.1111/ ajco.12295.

14. Sahebjamee M, Mansourian A, Hajimirzamohammad M, Zadeh MT, Bekhradi R, Kazemian A, et al. Comparative efficacy of Aloe vera and benzydamine mouthwashes on radiation-induced oral mucositis: a triple-blind, randomised, controlled clinical trial. Oral Health Prev Dent. 2015;13(4):309-15. doi: 10.3290/j.ohpd.a33091.

15. Saldanha SP, Almeida VD. a comparative study to assess the effectiveness of turmeric mouth wash versus saline mouth wash on treatment induced oral mucositis (TIOM) in a selected hospital at Mangalore. J Clin Res Bioeth. 2014;5(6):200. doi: 10.4172/2155-9627.1000200.

16. Deshmukh RA, Bagewadi AS. Comparison of effectiveness of curcumin with triamcinolone acetonide in the gel form in treatment of minor recurrent aphthous stomatitis: a randomized clinical trial. Int J Pharm Investig. 2014;4(3):138-41. doi: 10.4103/2230-973x.138346.

17. Elad S, Meidan I, Sellam G, Simaan S, Zeevi I, Waldman E, et al. Topical curcumin for the prevention of oral mucositis in pediatric patients: case series. Altern Ther Health Med. 2013;19(3):21-4

18. Chitapanarux I, Tungkasamit T, Petsuksiri J, Kannarunimit D, Katanyoo K, Chakkabat C, et al. Randomized control trial of benzydamine $\mathrm{HCl}$ versus sodium bicarbonate for prophylaxis of concurrent chemoradiation-induced oral mucositis. Support Care Cancer. 2018;26(3):879-86. doi: 10.1007/s00520-017-3904-4.

19. Rosdianto AM, Puspitasari IM, Lesmana R, Levita J. Inhibitory activity of Boesenbergia rotunda (L.) Mansf. rhizome towards the expression of Akt and NF-KappaB p65 in acetic acid-induced Wistar rats. Evid Based Complement Alternat Med. 2020;2020:6940313. doi: $10.1155 / 2020 / 6940313$

20. Umar MI, Asmawi MZ, Sadikun A, Majid AM, Al-Suede FS, Hassan LE, et al. Ethyl-p-methoxycinnamate isolated from Kaempferia galanga inhibits inflammation by suppressing interleukin-1, tumor necrosis factor- $\alpha$, and angiogenesis by blocking endothelial functions. Clinics (Sao Paulo).
2014;69(2):134-44. doi: 10.6061/clinics/2014(02)10.

21. Nittayananta W, Limsuwan S, Srichana T, SaeWong C, Amnuaikit T. Oral spray containing plantderived compounds is effective against common oral pathogens. Arch Oral Biol. 2018;90:80-5. doi: 10.1016/j. archoralbio.2018.03.002

22. Farooqui AA, Farooqui T, Madan A, Ong JH, Ong WY. Ayurvedic medicine for the treatment of dementia: mechanistic aspects. Evid Based Complement Alternat Med. 2018;2018:2481076. doi: 10.1155/2018/2481076

23. Kang YM, Komakech R, Karigar CS, Saqib A. Traditional Indian medicine (TIM) and traditional Korean medicine (TKM): aconstitutional-based concept and comparison. Integr Med Res. 2017;6(2):105-13. doi: 10.1016/j. imr.2016.12.003.

24. Chen YB, Tong XF, Ren J, Yu CQ, Cui YL. Current research trends in traditional Chinese medicine formula: a bibliometric review from 2000 to 2016. Evid Based Complement Alternat Med. 2019;2019:3961395. doi: $10.1155 / 2019 / 3961395$.

25. Arai YC, Makino I, Ikemoto T, Saisu H, Terajima Y, Owari K. Kampo for the treatment of pain in Japan: a review. Pain Ther. 2020;9(1):161-70. doi: 10.1007/s40122-020-00160-w.

26. Wang PL, Kaneko A. Introduction to Kampo medicine for dental treatment - Oral pharmacotherapy that utilizes the advantages of Western and Kampo medicines. Jpn Dent Sci Rev. 2018;54(4):197-204. doi: 10.1016/j.jdsr.2018.03.004.

27. Delfan B, Saki K, Bahmani M, Rangsaz N, Delfan M, Mohseni $\mathrm{N}$, et al. A study on anti-diabetic and antihypertension herbs used in Lorestan province, Iran. J Herbmed Pharmacol. 2014;3(2):71-6.

28. Balto H, Al-Sanie I, Al-Beshri S, Aldrees A. Effectiveness of Salvadora persica extracts against common oral pathogens. Saudi Dent J. 2017;29(1):1-6. doi: 10.1016/j. sdentj.2016.11.001.

29. Jettanacheawchankit S, Sasithanasate S, Sangvanich P, Banlunara W, Thunyakitpisal P. Acemannan stimulates gingival fibroblast proliferation; expressions of keratinocyte growth factor-1, vascular endothelial growth factor, and type I collagen; and wound healing. J Pharmacol Sci. 2009;109(4):525-31. doi: 10.1254/jphs.08204fp.

30. Lim SH, Choi CI. Pharmacological properties of Morus nigra L. (black mulberry) as a promising nutraceutical resource. Nutrients. 2019;11(2). doi: 10.3390/nu11020437.

31. Bayati Zadeh J, Moradi Kor Z, Karimi Goftar M. Licorice (Glycyrrhiza glabra Linn) as a valuable medicinal plant. Int J Adv Biol Biomed Res. 2013;1(10):1281-8.

32. Hewlings SJ, Kalman DS. Curcumin: a review of its effects on human health. Foods. 2017;6(10). doi: 10.3390/ foods6100092.

33. Al-Taie A, Al-Shohani AD, Albasry Z, Altaee A. Current topical trends and novel therapeutic approaches and delivery systems for oral mucositis management. J Pharm Bioallied Sci. 2020;12(2):94-101. doi: 10.4103/jpbs. JPBS_198_19. 